\title{
SYMPOSIUM ON RHEOLOGICAL PROPERTIES OF ERYTHROCYTES IN HEALTH AND DISEASE
}

Organized jointly by the International Society of Biorheology and the International Society of Hematology on 6 August 1970, during the XIII International Congress of Hematology, Munich, Germany

THE SYMPosium had as original moderators Dr. Leopold Dintenfass, Sydney, Australia and Dr. H. Schmid-Schönbein, Munich, Germany. It was organized with the consent of the President of The International Society of Biorheology, A. L. Copley, who also as Co-Editorin-Chief of Biorheology, attended the meeting at Munich. Since Dr. Dintenfass could not participate in the symposium, it was chaired by Dr. Schmid-Schönbein.

In order to expedite the publication of papers presented at this symposium, the Editors-inChief made arrangements with the publisher, Pergamon Press Ltd., to have a number of these papers published in subsequent issues of Biorheology. An editorial experiment was made by the appointment of Guest Editors whose task was to aid A. L. Copley as Co-Editor-in-Chief in appraising the presented papers, each to be done by two referees. The maintenance of the high standards, set by the editorial policy of Biorheology, and rapid publication could thus be secured. The difference from our usual editorial procedure lies in a new practice in not keeping the anonymity of the referee, but making it possible for the guest editor to communicate directly with the authors in recommending to them revisions or changes in the manuscript, as the referees require. The final decision of acceptance of the paper still rested with the Editors-in-Chief. We should like to thank the Guest Editors, Professors Shu Chien, Hemorheology Laboratory, College of Physicians and Surgeons, Columbia University, New York, N.Y., Dr. Joseph F. Gross, Rand Corporation, Santa Monica, California, and Professor P. L. La Celle, Department of Biophysics, University of Rochester, Rochester, N.Y., as well as other referees they consulted, for their cooperation in this editorial experiment.

The following communications represent the first part of the symposium papers.

A. L. COPLEY

G. W. SCOTT BLAIR 